To cite this article:

Guangliang Xi, ${ }^{\mathrm{a}}$ Feng Zhen, ${ }^{\mathrm{a}}$ Xinyu (Jason) Cao ${ }^{\mathrm{b}}$ \& Feifei Xu ${ }^{\mathrm{c}}, 2018$ The interaction between e-shopping and store shopping: Empirical evidence from Nanjing, China. Transportation Letters: the international journal of transportation research.

https://www.tandfonline.com/doi/full/10.1080/19427867.2018.1546797 


\title{
The interaction between e-shopping and store shopping: Empirical evidence from Nanjing, China
}

\begin{abstract}
The rise of e-shopping significantly changes the way that people shop. Transportation planners have a keen interest in the substitution of e-shopping for store shopping and its impact on transportation systems. The literature offers mixed findings on the relationship between online and store shopping. Few studies have explored this relationship in China where e-shopping has proliferated and retail land use and transportation systems have evolved. Using data gathered from adult internet users in Nanjing, this paper applies structural equation modelling to investigate the relationships among store shopping, online shopping, and online searching. The results show that online and store shopping have a positive association, however, the effect is from the latter to the former. Online searching positively influences both online and store shopping. These results imply that e-shopping as an information channel promotes store shopping.
\end{abstract}

Keywords: China; information and communication technology; internet shopping;

online shopping; shopping travel 


\section{Introduction}

The proliferation of e-commerce has greatly promoted business to consumer (B2C) eshopping (or online shopping), which has a substantial influence on how people shop in stores and live their lives. In 2017, online retail transactions throughout the world reached $\$ 2,300$ billion, accounting for $10.2 \%$ of global total retail sales (CIECC 2017). Online shopping could impact the shopping modal share, the volume of purchases, as well as per capita spending (Mokhtarian 2004). The impacts suggest transformations of the consumption economy, retail land use, shopping behavior, and travel behavior. Eshopping imposes great challenges for traditional brick-and-mortar stores; for example, Sears, once the largest retailer in the USA, filed for bankruptcy in October 2018. Eshopping also has important implications for shopping travel and transportation systems (Cao 2009). Since shopping travel accounts for about one-fifth of household vehicular trips in the USA, European countries, and China (Hu and Reuscher 2004;Shaanxi Bureau of Statistics 2016), and e-shopping has the potential to replace personal shopping trips, studying the impacts of e-shopping on traditional shopping is important to learn the impact on transportation systems.

Many studies examine the impact of e-shopping on store shopping (Rotem-Mindali and Weltevreden 2013). However, there has been limited attention to the reverse impact: from shopping at a store to e-shopping. More importantly, most empirical studies use data from the USA and the Netherlands, as well as other developed countries (Caldervvood and Freathy 2014;Cao, Douma, and Cleaveland 2010;Farag, Krizek, and Dijst 2006; Ren and Kwan 2009). Few have focused on developing countries, such as China, where e-shopping has proliferated, and travel mode choice and shopping environment differ from developed countries. Therefore, transportation planners should explore the relationship between e-shopping and store shopping trips in the context of China. 
Using a 2015 sample of 881 adult internet users in Nanjing, China, this paper explores the relationship between e-shopping and store shopping for two types of products: daily goods and clothing. Structural equation modeling (SEM) is adopted to analyze the interactions among online searching frequency, online purchasing propensity, and store purchasing propensity. This study will address the following research questions: How are online searching, online purchasing, and store purchasing associated with each other? Do the findings in China differ from developed countries?

The paper is organized as follows. The next section reviews the literature on the relationship between e-shopping and store shopping. Section 3 presents the data, variables, and modeling approach. Section 4 presents and discusses the results. The final section summarizes the key findings of this paper and makes recommendations for future research.

\section{Literature Review}

Transportation planners and geographers propose four potential effects of information and communication technologies (ICTs) on personal travel: substitution, complementarity, modification, and neutrality (Salomon 1986;Mokhtarian 1990). A substitution effect denotes that online shopping replaces store-shopping trips. A complementarity effect indicates that online shopping stimulates additional travel to stores. For example, an individual travels to the store to experience a product after finding it online, or online shoppers make a special trip to pick up an item purchased online (Zhai et al. 2016;Lee et al. 2017). Modification occurs when online shopping changes shopping trip characteristics, such as travel mode, travel time, and travel distance. Neutrality means that there is no relationship between online shopping and store shopping.

Many scholars conduct empirical studies of these conceptual connections. Most of the studies focus on the influence of e-shopping on store shopping and produce varied outcomes. Several studies substantiate substitution effects in Northern California, San 
Francisco Bay Area, Scottish isles, and Israel (Caldervvood and Freathy 2014;Ferrell 2004;Circella and Mokhtarian 2010;Rotem-Mindali 2010;Weltevreden and Rietbergen 2007). By contrast, Farag, Schwanen, and Dijst (2005) found that e-shopping complements store shopping in the Netherlands. Hiselius, Rosqvist, and Adell (2015) found that shopping online might have a neutral effect on store shopping trips in Sweden. Cao (2012) and Zhai et al. (2016) conclude that the effect of online shopping on store shopping is complicated because the internet facilitates a hybrid shopping process.

However, it is also possible that store shopping influences online shopping. Traditional retailers adopt various strategies to counter competition from online retailers. For example, many bookstores accommodate coffee and leisure activities. Empirically, Weltevreden and Rietbergen (2007) found that the perceived attractiveness of city centers affects individuals' shopping choice between store and online channels. The accessibility and attractiveness of stores appear to have a negative effect on online shopping, after controlling for sociodemographic, behavioral, and spatial variables.

Because online shopping and store shopping may influence one another, a few studies explore the bidirectional relationships. Using the data of 826 respondents to a shopping survey in four municipalities in the Netherlands, Farag et al. (2007) adopted a SEM to study the connections among the frequencies of online searching, online buying, and non-daily shopping trips. After accounting for the confounding influences of demographics, shopping attitudes, and lifestyle, they concluded that online searching frequency is positively associated with store shopping frequency, which in turn positively affects online buying frequency. However, they did not find a significant effect of online shopping on store shopping. Adapted from Farag et al. (2007), Cao, Xu, and Douma (2012) also developed a SEM using the data of 539 adult internet users in the Twin Cities, USA. After controlling for demographics, shopping attitudes, and internet-related attributes, they concluded that online searching is complementary to both online buying and store shopping, and that online buying positively affects store 
shopping. They did not find a significant influence of store shopping on online buying, however. Ding and Lu (2017) applied a SEM to the GPS-based diary data in Beijing and found that online purchasing and store purchasing promote one another. Zhou and Wang (2014) developed a SEM using the 2009 US National Household Travel Survey data and concluded that online shopping has a complementary effect on shopping trips but shopping trips tend to substitute for online shopping. In summary, the internet as an information channel promotes shopping online and at stores, but the way that online shopping and store shopping interact is inconclusive.

Furthermore, most studies regarding the relationships between online shopping and store shopping use data from developed countries. The findings may not be generalizable to China, where shopping environment and retail land use differ greatly from developed countries. In the USA, zoning regulations separate commercial establishments from residential land uses, particularly in suburban neighborhoods. Bigbox stores and shopping malls concentrated at the edge of urban centers or suburbs are dominant shopping areas (Ren and Kwan 2009). In Europe, shopping areas are often clustered in traditional urban centers (Weltevreden and Rietbergen 2007). In urban China, shopping areas are usually classified as central commercial districts, sub-central commercial districts, and community commercial centers, based on commercial configuration standards required by national planning laws. Recently, multi-function business centers (known as urban complexes with office, shopping mall, catering, leisure facilities and other services) have proliferated in the city center or new town centers with convenient access by transit (Wang and Lu 2012). More importantly, commercial land uses for daily shopping are usually mixed with residential land uses (Xi et al. 2014).

Shopping travel and online shopping behavior also differ between China and developed countries. Because of the difference in the distribution of commercial land uses, the average distance for shopping trips in Chicago doubles that in Beijing(Zhao, Chai, and Kwan 2014). Transit and walking are dominant modes of shopping trips in China, while 
personal vehicles are prevalent in developed countries (Zhen et al. 2016). Chinese are more willing to adopt online shopping, partly because transit is not as convenient as personal vehicles for shopping trips. According to a report from China Internet Network Information Center (2016), the number of e-shoppers reached 413 million by December 2015, accounting for $60 \%$ of all internet users in China, and internet sales increased from RMB 510 billion in 2010 to RMB 3.88 trillion (or about \$600 billion) in 2015, accounting for $13 \%$ of total retail sales. This share is higher than the USA (6.4\%) (Census Bureau 2015) and the Netherlands (10\%)(Thuiswinkel 2015). The difference in e-shopping penetration could lead to different online shopping behaviors. For example, online orders of takeout food with delivery are very common in China.

Taken together, previous studies often emphasize the influence of online shopping on store shopping, overlooking the reverse impact. Furthermore, the findings from developed countries are not readily generalizable to developing countries. Therefore, the association between online shopping and store shopping in China merits further exploration.

It is worth noting that Zhen et al. (2016) applied a joint ordered probit model to the same data to explore the influence of online shopping on store shopping. They substantiated the influence. However, they ignored the potential influence of store shopping on online shopping. The present study employs a SEM to examine the interactions among online searching, online shopping, and store shopping. Thus, it offers a more comprehensive understanding of the relationships. Contrary to Zhen et al. (2016), this study concludes that the relationship between online shopping and store shopping is from the latter to the former, suggesting that the model specification in Zhen et al. (2016) is flawed. We also discussed extensively why the positive effect of store shopping on online shopping is plausible. Furthermore, in Zhen et al. (2016), online searching frequency does not have a significant effect on store shopping once online shopping frequency is controlled for. However, this study finds that it positively affects the propensity for both online shopping and store shopping. 


\section{Methodology}

\subsection{Data}

This paper uses data from a household survey conducted in Nanjing, China, collected in Spring 2015. Nanjing, located in the Yangtze River Delta, is the capital of Jiangsu Province. By 2015, Nanjing had 8.24 million permanent residents. The Nanjing metropolitan area consists of 11 administrative districts. This study focuses on eight districts which cover most of the urbanized areas of Nanjing (about 6.36 million permanent residents). We chose two to five sub-districts (jiedao in Chinese, the lowest administrative organization in China) to represent different locations within each district. The total number of sub-districts is 24 . In each of the sub-districts, one to three neighborhoods were selected based on access to metro transit and shopping accessibility. In particular, we chose neighborhoods next to or away from metro stations, and neighborhoods close to or away from business centers and supermarkets. Forty-two neighborhoods were selected for sampling (Fig. 1).

[Insert Figure 1 here]

The population of this study is adult internet users in Nanjing. We collected the data through face-to-face interviews with a structured questionnaire. Within the selected neighborhoods, respondents were located through knocking on doors or inviting residents into neighborhood open spaces. To ensure random selection of respondents for in-home interviews, we invited the adult interviewee whose birthday was closest to the survey date to participate. If that person was not available, another household member was invited to respond. Because adults are more likely to be at home during non-working hours, we conducted the survey in the evening on weekdays and during the day on weekends. A USB flash drive served as an incentive for survey participation. We invited/knocked on the door of 2,874 households, but only 1,496 households answered. Ultimately, 1,032 respondents completed the survey. The survey response 
rate was 35.9\% (=1,032/2,874). After removing 21 non-adult participants and 130 questionnaires with many missing responses, there were 881 participants.

Table 1 shows the descriptive statistics of the sample. On average, respondents are more likely to be female, younger, highly-educated, and have relatively convenient conditions conducive to shopping activities, such as owning a driver's license, using ebanking, or regular internet usage (Table 1). However, since we aim to find the relationships of other variables to shopping behavior rather than illustrating its univariate distribution, the overrepresentation of certain groups of people is not likely to materially influence the outcomes of a multivariate analysis (Babbie 2015).

[Insert Table 1 here]

\subsection{Variables}

\section{Shopping behavior}

The key variables are e-shopping and store shopping behavior. In the survey, we asked respondents to indicate how often they purchase four types of goods-clothing (including shoes and bags), daily goods, books, and electronics—-for themselves or their household at traditional stores and through the internet, respectively, on a six-point scale ranging from "very rarely" (1) to "four times per month or more” (6). Clothing and daily goods were purchased more frequently than books and electronics, no matter whether they were purchased online or at stores (Table 2). This finding is consistent with the report by China Internet Network Information Center (2016). Respondents were also asked to report how often they looked for information about products and/or stores using the internet on a five-point scale ranging from "very rarely” (1) to "Once a day or several times” (5). About half of the respondents searched for product information one or more times per week.

[Insert Table 2 here] 


\section{Shopping attitudes}

Although online shopping could reduce cost and travel time, some people may enjoy shopping in physical stores. In the survey, respondents were asked to indicate the degree to which they agree with 18 statements on a five-point Likert scale. The statements were drawn from Mokhtarian, Ory, and Cao (2009) and adjusted according to the local social and culture context (Zhen et al. 2016). Because some of the statements are correlated, we used an exploratory factor analysis to extract latent constructs. We obtained five factors: novelty seeking, shopping enjoyment, cost consciousness, spontaneous shopper and time consciousness (Table 3).

[Insert Table 3 here]

\section{Internet use}

Internet use influences e-shopping activities (Cao, $\mathrm{Xu}$, and Douma 2012). The more individuals are online, the more likely they are to conduct online shopping. We measured internet use through two observed variables: years of using internet and duration of internet access. In the survey, respondents were asked to report how many years they have used the internet on a five-point scale from "less than 1 year" (1) to "more than 10 years" (5). The duration of internet access was measured by the time respondents spent on the internet with a five-point scale from "one or a few hours per month" (1) to "more than 5 hours a day" (5).

\section{Socio-demographics}

The survey included a list of socio-demographic variables such as gender, age, educational background, employment status, auto ownership, household structure and 
household income. Respondents were also asked for their household shopping responsibility and whether they owned a driver's license and credit/debit cards.

\subsection{Conceptual model and analysis approach}

Following Cao, Xu, and Douma (2012), we proposed a conceptual model (Fig.2). We assumed that there are bidirectional influences between each pair of the three variables: online searching, online shopping, and store shopping. We further hypothesized that socio-demographics, internet use, and shopping attitudes affect these three variables. Since a single-equation model cannot address these complex relationships, we employed a structural equations model.

[Insert Figure 2 here]

A SEM with latent variables includes measurement models and a structural model. A measurement model identifies a latent variable underlying a few observed variables. The structural model depicts the influences of exogenous variables on endogenous variables and the interactions among endogenous variables. Specifically, a SEM can be illustrated as follows (Duncan 2014;Fox, Nie, and Byrnes 2009; Kline 2015):

$$
\begin{gathered}
x=\Lambda_{x} \xi+\delta \\
y=\Lambda_{y} \eta+\varepsilon \\
\eta=\mathrm{B} \eta+\Gamma \xi+\zeta
\end{gathered}
$$

where

$x$ is a $(p \times 1)$ column vector of $p$ exogenous observed variables;

$\xi$ is a $(m \times 1)$ column vector of $m$ exogenous latent variables;

$\Lambda_{x}$ is a $(p \times m)$ matrix of factor loadings relating exogenous observed variables to exogenous latent variables;

$\delta$ is $a(p \times 1)$ column vector of measurement errors;

$y$ is a $(q \times 1)$ column vector of $q$ endogenous observed variables;

$\eta$ is $a(n \times 1)$ column vector of $n$ endogenous latent variables; 
$\Lambda_{y}$ is a $(q \times n)$ matrix of factor loadings relating endogenous observed variables to endogenous latent variables;

$\varepsilon$ is $a(q \times 1)$ column vector of measurement errors;

$\mathrm{B}$ is a $(n \times n)$ matrix of structural parameters depicting the relationships among latent endogenous variables;

$\Gamma$ is a $(n \times m)$ matrix of structural parameters depicting the influences of latent exogenous variables on latent endogenous variables; and

$\zeta$ is a $(n \times 1)$ matrix of errors.

The detailed introduction and mathematical method of the SEM can be found in Kline (2015).

We developed the model using general analysis and maximum likelihood (ML) estimation in Mplus 5.0. First, we used confirmatory factor analysis to substantiate the relationship between latent variables and their observed indicators in the measurement models. Second, we estimated a structural model to identify significant paths among variables. Although the ML approach requires the variables to follow a multivariate normal distribution, a SEM with ordinal and dummy variables (i.e., gender) could be estimated in Mplus (Muthén and Muthén 2012).

One advantage of SEM is that it can estimate direct effects, indirect effects, and total effects simultaneously. If variable $X$ impacts variable $Y$ without any mediating variables, this impact represents a direct effect from $X$ on $Y$ (Fig. 3). On the contrary, if variable $X$ impacts variable $Y$ through at least one mediating variable $Z$, this impact is an indirect effect from $X$ to $Y$. The total effect is the sum of the direct effect and the indirect effect.

[Insert Figure 3 here]

\subsection{Modelling procedure}

We regard online shopping behavior as the latent propensity that underlies online shopping frequencies of the four types of products: clothing, daily goods, books, and 
electronics. This propensity is derived from a measurement model. It reflects individuals' proposition toward online shopping. Similarly, store shopping behavior is also treated as a latent variable underlying store shopping frequency of these four products. Online searching frequency, socio-demographics, internet use, and shopping attitudes are regarded as observed variables. It is worth noting that the model including all four products did not produce acceptable goodness of fit measures because books and electronics were purchased much less frequently than clothing and daily goods (see Table 2). We also attempted to develop a separated model for books and electronics. However, most of the relationships are insignificant. Therefore, we decided to remove books and electronics from further analysis. Our failure to capture the relationships for these two types of products may be attributable to the measurement scale that we used. Because they tend to be purchased much less frequently than clothing and daily goods, using the same measurement scale as clothing and daily goods cannot adequately capture the variation of shopping frequencies for books and electronics.

When developing the model, we initially kept the bidirectional relationships among the three endogenous variables (online shopping propensity, store shopping propensity, and online searching frequency) no matter whether these relationships are significant or not. Because the data include many exogenous variables, we dropped insignificant ones to obtain a parsimonious model. In particular, we deleted one exogenous variable at a time according to the significance level of exogenous variables and their interpretability. Once a parsimonious model was obtained, we started to drop insignificant links between the endogenous variables. For example, because the influence of online shopping propensity on store shopping propensity is insignificant while the effect of store shopping propensity on online shopping propensity is significant, we removed the link from online shopping propensity to store shopping propensity in the model specification. After the relationships among the endogenous variables are fixed, we allowed those dropped exogenous variables to reenter the model one by one to examine whether we omitted any significant variables. Once this process was completed, we obtained the final SEM. 


\section{Results and Discussion}

\subsection{Model results}

Table 4 presents goodness of fit indices of the final SEM. Because the Chi-square value increases as sample size increases, we used the relative Chi-square value alternatively (Bentler and Bonett 1980). According to Hu and Bentler (1999), all goodness of fit indices are acceptable.

[Insert Table 4 here]

Table 5 presents the standardized coefficients (representing the effects of a latent variable on its indicators) for the two latent endogenous variables: online shopping propensity and store shopping propensity. All the coefficients are larger than the frequently used rule of thumb cutoff point (0.3) (Lambert, Hogan, and Barton 2001).

[Insert Table 5 here]

This study focuses on the interactions among online searching frequency, online shopping propensity, and store shopping propensity. Table 6 presents the final SEM. Among the three pairs of bidirectional links in the conceptual model (Fig. 2), three links are statistically significant while the remaining three are insignificant after controlling for socio-demographics, internet use, and shopping attitudes. Specifically, online searching frequency is positively associated with store shopping propensity. This result is consistent with Farag et al. (2007) and Cao, Xu, and Douma (2012). Furthermore, the influence of online searching frequency on online shopping propensity is also positive. The more frequently individuals search via the internet, the more likely they are to buy products online. This finding is consistent with Cao, Xu, and Douma (2012). Moreover, the connection between store shopping and online shopping is from the former to the latter. In other words, individuals who shop frequently at stores tend to 
make online purchases. This result is consistent with Farag et al. (2007) but different from Cao, Xu, and Douma (2012).

[Insert Table 6 here]

Altogether, online searching promotes both online shopping and store shopping, and store shopping has a complementary effect on online shopping (Fig.4). When the propensity for store shopping increases by one standard deviation, the propensity for online shopping increases by an average of 0.460 standard deviations. In other words, the marginal impact of store shopping on online shopping is 0.460 . Furthermore, the marginal impact of online searching on online shopping is 0.318 . Therefore, the total effect of store shopping propensity on online shopping propensity exceeds that of online searching frequency.

[Insert Figure 4 here]

Regarding socio-demographics, women tend to search more frequently for product information online and they have a higher propensity to shop at stores than men. As expected, individuals with more household shopping responsibility tend to have a higher propensity for shopping both at stores and online. Younger people tend to conduct online searching more frequently than seniors, consistent with previous studies (Cao, Xu, and Douma 2012;Farag et al. 2007). Those who have a driver's license tend to have a higher propensity for store shopping, probably because shopping is more convenient by car than other modes (Ding and Lu 2017). Income is positively associated with store shopping propensity. However, it is not significantly associated with online shopping behavior, which differs from a study in developed countries (Cao, $\mathrm{Xu}$, and Douma 2012). The number of children is positively associated with online shopping propensity. Children may impose temporal constraints on caregivers' shopping travel, and online shopping helps relax their constraints. Moreover, parents 
may purchase clothes and daily goods for their children online because of the price advantages of online shopping.

Internet use facilitates e-shopping. In particularly, both indicators of internet use are positively correlated to online searching frequency. Furthermore, the more individuals use the internet, the higher their propensity is for online shopping.

Five shopping attitude variables are significantly associated with at least one aspect of e-shopping or store shopping. Those who seek novelty in shopping and/or enjoy shopping tend to search for product information online more often and have a higher propensity for store shopping. Cost-conscious people also tend to do more internet searching, presumably for good deals. Spontaneous shoppers tend to have a higher propensity for online shopping than others. As expected, time consciousness has a negative association with the propensity for store shopping.

\subsection{Discussion}

This study finds that store shopping has a positive association with online shopping. Why is there a complementary relationship between them? It may be spurious. For example, those who have a higher shopping responsibility tend to have a higher propensity for both store shopping and online shopping; demographics (such as gender and income) and some shopping attitudes may also be the variables antecedent to both online shopping and store shopping. However, since our SEM includes these factors, presumably we accounted for their confounding effects. Another important confounding factor is online searching behavior. With the proliferation of e-shopping, many e-retailers (such as Tmall and Jingdong) have become well-known in China. People often seek product features and customer reviews through the low-cost channel. Online advertisements often appear on various virtue platforms. Search engines (such as Baidu) also provide links to products. Overall, the rich product information on the internet may stimulate individuals' desire to purchase and hence shopping demand. Moreover, some e-retailers (such as Nike and Suning) have both online stores and 
physical stores. So online searching could lead to consumption in both shopping channels. In this study, we control for online searching frequency, so its effect is largely considered.

After controlling for all of these confounding factors, there is still a positive relationship between online shopping and store shopping. More importantly, the influence is from store shopping to online shopping, but not in the opposite direction. Here we present a few potential reasons. First, the main item purchased at traditional stores (such as overthe-range microwaves) may induce the demand for accessories that are available only online. In this case, store shopping generates online shopping.

Second, as a new channel, e-shopping partly meets traditional store shopping demand. Because many traditional retailers also operate internet stores, some demand for online shopping is derived from traditional shopping activities (Hsiao 2009). Individuals choose to order online because, for example, they want to avoid traveling to stores on a hot day or the products are not available at the store nearby. People may also diversify their shopping channels without changing their shopping travel demand. For instance, they may buy higher-value items in stores, but purchase cheaper goods online (Mokhtarian 2004;Lee et al. 2017). In these two cases, those with a higher shopping demand may divert more shopping to online stores while those with a smaller shopping demand may purchase less often through the internet. Accordingly, the observed relationship between store shopping and online shopping is positive.

Third, the fragmentation of shopping activities enabled by e-shopping helps explain the positive influence. Instead of purchasing a product through one single trip to stores, people may engage in a hybrid shopping process that involves both traditional stores and online stores (Cao 2012;Zhai et al. 2016). For example, some people may encounter a product of interest when they shop at a store, and decide to order online after comparing the product in the store with online retailers. Others may intentionally use traditional stores as a "showroom" and make a purchase online (Couclelis 2004;Rapp 
et al. 2015; Lee et al. 2017). These kind of interactions leads to an increase in online shopping but have no effect on store shopping travel.

Fourth, people may split a shopping activity into multiple parts. Without the availability of e-shopping, all goods (say, 10 items) would be purchased through a single trip to traditional stores. When online shopping is a viable alternative, six items may be purchased at traditional stores and four items may be purchased online. Furthermore, online purchases may be completed through multiple transactions at different times. In this case, the availability of online stores does not reduce store shopping frequency, but generates one or more online shopping activities. This phenomenon tends to be more prevalent in China than in the US. Vertical mixed use is common in Chinese residential neighborhoods as the first one or two floors of residential buildings along the street are often designated for commercial uses. This development pattern makes shopping convenient. In fact, many Chinese often stop at grocery stores on their way home. Mixed use enables less effort to make a shopping trip. Therefore, the growth of online shopping is not likely to reduce store shopping frequency. By contrast, commercial establishments are often segregated from residential neighborhoods in the USA. This development pattern is not conducive to shopping activities. Accordingly, online shopping may substitute for some shopping at stores. However, it should be kept in mind that this contrast may be applicable only to frequently-purchased goods because stores for infrequently-purchased goods (such as furniture and electronics) are not widely available in China.

Although this study does not find a significant effect of online shopping on store shopping, the proliferation of e-shopping does affect travel. Some shoppers may search for product information online and then travel to a store to make the purchase. This is true in China, where people often browse for products through various mobile shopping Apps even if they do not have a specific shopping purpose. Furthermore, as Chinese governments launch smart city initiative, more Chinese have access to the internet. The 
low-cost channel allows more shoppers to obtain product information to generate new shopping demand and trips to stores.

Even if all new demand is met through online shopping, freight travel for product delivery will continue to impose burden on transportation systems. This is problematic in China, where small three-wheel vehicles or motorcycles are used for the "last mile" delivery. The drivers of these vehicles at times do not obey traffic regulations, leading to traffic accidents and congestion. Furthermore, the complementary effect of store shopping on online shopping will deteriorate this problem.

\section{Conclusions}

Using a household survey of adult internet users in Nanjing, this study employs a structural equations model to investigate the interactions between e-shopping and traditional store shopping. Model results show that in terms of direct effects, online searching frequency has positive impacts on the propensities for both online and store shopping. There is also a positive association between online shopping and store shopping propensities, but the impact is from store shopping to online shopping, rather than the commonly-assumed direction from online shopping to store shopping in the literature. Therefore, online shopping diversifies the ways in which frequent buyers shop. Although transportation planners expect e-shopping to substitute for store shopping, this study concludes that online shopping has a neutral effect on store shopping, and that e-shopping as an information channel promotes store shopping. These results imply that e-shopping is not likely to be a solution to traffic congestion, particularly because the extensive product information on the internet greatly reduces searching costs.

This study has a few limitations. First, we do not find a significant influence of online shopping on store shopping. Because the analysis is based on cross-sectional data, we are unable to capture how individuals change their store shopping behavior after they adopt online shopping. Longitudinal studies are desirable to discern the causal 
relationship between online shopping and store shopping. Second, we measure many variables in ordinal scales and treat them as numeric variables. This method assumes an equal distance between numerals that define the categories. Alternatively, we could treat ordinal variables as nominal ones. However, the problem is that the information on the ordering is lost. That is, both methods have pros and cons. Because it is a common practice to treat ordinal variables as numeric in the measurement models of SEM, we value the consistency and adopt this method. Third, we use the same measurement scale for both frequently-purchased and infrequently-purchased goods. This practice leads to the low variation in the shopping frequency for books and electronics, which may explain why the models including these two types of goods fail. We should have used different measurement scales for goods with different shopping frequencies.

Future studies should explore the associations between online shopping and store shopping for infrequently-purchased goods. The findings for frequently-purchased goods cannot be generalized to infrequently-purchased goods due to the differences in store distribution and shopping behavior. Moreover, it usually takes two or more days for online retailers to deliver daily goods to customers. Recently, same day delivery has become prevalent for grocery shopping due to the proliferation of mobile shopping apps (i.e., Walmart grocery pickup and delivery services in USA, and Meituan and Dada-JD Daojia in China). With same day delivery, individuals build an online basket, place the order and pay for it. Then, they choose a desirable time window for the order to be delivered on the same day. Anecdotes suggest that the same day delivery of daily goods may substitute for store shopping and associated travel. Future studies should examine the relationship between e-shopping through same day delivery and store shopping for daily goods, and compare the differences between same day delivery e-shopping and conventional delivery e-shopping. 


\section{Acknowledgements}

This study was funded by the National Natural Science Foundation of China (No. 41571146; 4170117) and the China Postdoctoral Science Foundation (No. 2016M600393). Thanks to Dr. Patricia Mokhtarian for her advice on survey design and administration. 


\section{References}

Babbie, E. R. 2015. The Practice of Social Research. 14th ed. Boston: Cengage Learning.

Bentler, P. M., and D. G. Bonett. 1980. "Significance tests and goodness of fit in the analysis of covariance structures." Psychological bulletin 88 (3):588.

Caldervvood, E., and P. Freathy. 2014. "Consumer mobility in the Scottish isles: The impact of internet adoption upon retail travel patterns." Transportation Research Part a-Policy And Practice 59:192-203.

Cao, X. J., Z. Xu, and F. Douma. 2012. "The interactions between e-shopping and traditional in-store shopping: an application of structural equations model." Transportation 39 (5):957-974.

Cao, X. Y. 2009. "E-Shopping, Spatial Attributes, and Personal Travel A Review of Empirical Studies." Transportation Research Record (2135):160-169. doi: 10.3141/2135-19.

Cao, X. Y. 2012. "The relationships between e-shopping and store shopping in the shopping process of search goods." Transportation Research Part A: Policy and Practice 46 (7):993-1002.

Cao, X. Y., F. Douma, and F. Cleaveland. 2010. "Influence of E-Shopping on Shopping Travel Evidence from Minnesota's Twin Cities." Transportation Research Record (2157):147-154.

Census Bureau. 2015. "Estimated Quarterly U.S. Retail Sales (Adjusted): Total and ECommerce." http://www.census.gov/retail/.

China Internet Network Information Center. 2016. Report on China 's online shopping market in 2015. Beijing: China Internet Network Information Center.

CIECC. 2017. Global E-commerce. Beijing: China International Electronic Commerce Center.

Circella, G., and P. L. Mokhtarian. 2010. "Complementarity or substitution of online and in-store shopping: an empirical analysis from Northern California." the 89th transportation research board annual meeting, Washington

Couclelis, H. 2004. "Pizza over the Internet: e-commerce, the fragmentation of activity and the tyranny of the region." Entrepreneurship \& Regional Development 16 (1):41-54.

Ding, Y., and H. P. Lu. 2017. "The interactions between online shopping and personal activity travel behavior: an analysis with a GPS-based activity travel diary." Transportation 44 (2):311-324.

Duncan, O. D. 2014. Introduction to structural equation models: Elsevier.

Farag, S., K. J. Krizek, and M. Dijst. 2006. "E-shopping and its relationship with instore shopping: Empirical evidence from the Netherlands and the USA." Transport Reviews 26 (1):43-61.

Farag, S., T. Schwanen, and M. Dijst. 2005. "Empirical investigation of online searching and buying and their relationship to shopping trips." Transportation research record 1926 (1):242-251.

Farag, S., T. Schwanen, M. Dijst, and J. Faber. 2007. "Shopping online and/or in- 
store? A structural equation model of the relationships between e-shopping and in-store shopping." Transportation Research Part A: Policy and Practice 41 (2):125-141. doi: 10.1016/j.tra.2006.02.003.

Ferrell, C. 2004. "Home-based teleshoppers and shopping travel: do teleshoppers travel less?" Transportation Research Record (1894):241-248.

Fox, J., Z. Nie, and J. Byrnes. 2009. sem: structural equation models (Computer software manual).

Hiselius, L. W., L. S. Rosqvist, and E. Adell. 2015. "Travel Behaviour of Online Shoppers in Sweden." Transport and Telecommunication Journal 16 (1):2130. doi: 10.1515/ttj-2015-0003.

Hsiao, M. H. 2009. "Shopping mode choice: Physical store shopping versus eshopping." Transportation Research Part E: Logistics and Transportation Review 45 (1):86-95.

Hu, L., and P. M. Bentler. 1999. "Cutoff criteria for fit indexes in covariance structure analysis: Conventional criteria versus new alternatives." Structural equation modeling: a multidisciplinary journal 6 (1):1-55.

Hu, P. S., and T. R. Reuscher. 2004. Summary of Travel Trends: 2001 National Household Travel Survey. U.S.: Department of Transportation.

Kline, R. B. 2015. Principles and practice of structural equation modeling: Guilford publications.

Lambert, E. G., N. L. Hogan, and S. M. Barton. 2001. "The impact of job satisfaction on turnover intent: a test of a structural measurement model using a national sample of workers." The Social Science Journal 38 (2):233-250.

Lee, R. J., I. N. Sener, P. L. Mokhtarian, and S. L. Handy. 2017. "Relationships between the online and in-store shopping frequency of Davis, California residents." Transportation Research Part A: Policy and Practice 100:40-52. doi: 10.1016/j.tra.2017.03.001.

Mokhtarian, P. L. 1990. "A typology of relationships between telecommunications and transportation." Transportation Research Part A: General 24 (3):231242.

Mokhtarian, P. L. 2004. "A conceptual analysis of the transportation impacts of B2C e-commerce." Transportation 31 (3):257-284.

Mokhtarian, P. L., D. T. Ory, and X. Cao. 2009. "Shopping-Related Attitudes: A Factor and Cluster Analysis of Northern California Shoppers." Environment and Planning B: Planning and Design 36 (2):204-228. doi: 10.1068/b34015t.

Muthén, L., and B. Muthén. 2012. "Mplus user’s guide. 2010." Los Angeles, CA: Muthén \& Muthén 6.

Rapp, A., T. L. Baker, D. G. Bachrach, J. Ogilvie, and L. S. Beitelspacher. 2015. "Perceived customer showrooming behavior and the effect on retail salesperson self-efficacy and performance." Journal of Retailing 91 (2):358369.

Ren, F., and M. P. Kwan. 2009. "The impact of geographic context on e-shopping behavior." Environment And Planning B-Planning \& Design 36 (2):262-278. Rotem-Mindali, O. 2010. "E-tail versus retail: The effects on shopping related travel 
empirical evidence from Israel." Transport Policy 17 (5):312-322. doi: http://dx.doi.org/10.1016/j.tranpol.2010.02.005.

Rotem-Mindali, O., and J. W. J. Weltevreden. 2013. "Transport effects of ecommerce: what can be learned after years of research?" Transportation 40 (5):867-885.

Salomon, I. 1986. "Telecommunications and travel relationships: a review." Transportation Research Part A: General 20 (3):223-238.

Shaanxi Bureau of Statistics. 2016. "Investigation on the Characteristics of Travel Behavior in China." accessed 14 Jan. http://www.sei.gov.cn/ShowArticle.asp?ArticleID=276681.

Thuiswinkel. 2015. "Dutch spending in 2014 almost $€ 14$ billion online." accessed 3 Jan. https://www.thuiswinkel.org/nieuws/2721/nederlanders-besteden-in-2014bijna-14-miljard-online.

Wang, M. F., and S. Lu. 2012. "Substitution or complementarity: Online shopping and its relationship with traditional shopping behavior." Human Geography 27 (3):44-49.

Weltevreden, J. W., and T. V. Rietbergen. 2007. "E - shopping versus City Centre Shopping: The role of Perceived City Centre Attractiveness." Tijdschrift voor economische en sociale geografie 98 (1):68-85.

Xi, G., F. Zhen, X. Wang, and X. Qin. 2014. "Study on the influencing factors and spatial characteristics of residents' online consumption in Nanjing." Geographical Research 33 (2):284-295.

Zhai, Q., X. Cao, P. L. Mokhtarian, and F. Zhen. 2016. "The interactions between eshopping and store shopping in the shopping process for search goods and experience goods." Transportation 44 (5):885-904. doi: 10.1007/s11116016-9683-9.

Zhao, Y., Y. Chai, and M.-P. Kwan. 2014. "Comparison of urban residents' travel behavior in China and the US: A case study between Beijing and Chicago." Geographical Research 33 (12):2275-2285.

Zhen, F., X. Cao, P. L. Mokhtarian, and G. Xi. 2016. "Associations between online purchasing and store purchasing for four types of products in Nanjing, China." Transportation Research Record: Journal of the Transportation Research Board (2566):93-101.

Zhou, Y., and X. Wang. 2014. "Explore the relationship between online shopping and shopping trips: An analysis with the 2009 NHTS data." Transportation Research Part A: Policy and Practice 70:1-9. doi: 10.1016/j.tra.2014.09.014. 
Table 1. The descriptive statistics of samples.

\begin{tabular}{|c|c|}
\hline Variables & Statistics \\
\hline Mean age & 31.59 \\
\hline \multicolumn{2}{|l|}{ Gender } \\
\hline Male & $41.7 \%$ \\
\hline Female & $58.3 \%$ \\
\hline \multicolumn{2}{|l|}{ Driver’s license } \\
\hline Yes & $60.8 \%$ \\
\hline No & $39.2 \%$ \\
\hline \multicolumn{2}{|l|}{ E-banking } \\
\hline Yes & $87.2 \%$ \\
\hline No & $12.8 \%$ \\
\hline \multicolumn{2}{|l|}{ Household income per month (RMB) } \\
\hline Less than 3000 & $10.7 \%$ \\
\hline $3000-5000$ & $20.9 \%$ \\
\hline $5000-7000$ & $21.5 \%$ \\
\hline $7000-10000$ & $18.2 \%$ \\
\hline $10000-15000$ & $14.4 \%$ \\
\hline $15000-20000$ & $7.8 \%$ \\
\hline \multicolumn{2}{|l|}{ Education } \\
\hline Middle school or less & $4.3 \%$ \\
\hline High school or Technical secondary school & $11.1 \%$ \\
\hline Junior college & $23.3 \%$ \\
\hline Undergraduate & $46.8 \%$ \\
\hline Graduate or above & $14.5 \%$ \\
\hline \multicolumn{2}{|l|}{ Number of children } \\
\hline No child & $61.7 \%$ \\
\hline One child & $34.2 \%$ \\
\hline Two children or more & $4.1 \%$ \\
\hline \multicolumn{2}{|l|}{ Years of using internet } \\
\hline 2-years or less & $4.7 \%$ \\
\hline 2-5 years & $20.2 \%$ \\
\hline 5-10years & $42.6 \%$ \\
\hline More than 10 years & $32.6 \%$ \\
\hline \multicolumn{2}{|l|}{ Duration of internet access } \\
\hline Several hours or less per week & $6.0 \%$ \\
\hline 1-2 hours per day & $25.4 \%$ \\
\hline 3-4 hours per day & $32.2 \%$ \\
\hline More than 5 hours a day & $36.3 \%$ \\
\hline
\end{tabular}

$\mathrm{N}=881$ 
Table 1. Online purchasing, store purchasing, and online searching behaviour.

\begin{tabular}{|c|c|c|c|c|c|c|c|c|c|c|}
\hline \multirow{3}{*}{$\begin{array}{l}\text { Purchasing } \\
\text { frequency } \\
\text { Very rarely }\end{array}$} & \multicolumn{2}{|c|}{ Clothing } & \multicolumn{2}{|c|}{ Books } & \multicolumn{2}{|c|}{ Daily goods } & \multicolumn{2}{|c|}{ Electronics } & \multirow{2}{*}{\multicolumn{2}{|c|}{$\begin{array}{c}\text { Online searching } \\
\text { frequency }\end{array}$}} \\
\hline & Online & Store & Online & Store & Online & Store & Online & Store & & \\
\hline & 25.8 & 28.8 & 55.8 & 71.0 & 31.1 & 16.1 & 80.6 & 83.1 & Very rarely & 21.1 \\
\hline $\begin{array}{l}\text { Once every two } \\
\text { months }\end{array}$ & 19.4 & 25.6 & 21.5 & 14.6 & 13.3 & 12.4 & 11.6 & 11.4 & $\begin{array}{l}\text { Less than once a } \\
\text { month }\end{array}$ & 9.1 \\
\hline Once per month & 19.1 & 23.9 & 13.1 & 8.5 & 26.3 & 21.2 & 3.9 & 3.1 & $\begin{array}{l}\text { Once a month } \\
\text { or several times }\end{array}$ & 21.4 \\
\hline $\begin{array}{l}\text { Twice per } \\
\text { month }\end{array}$ & 14.3 & 12.7 & 5.6 & 2.4 & 13.9 & 21.4 & 2.1 & 1.0 & $\begin{array}{l}\text { Once a week or } \\
\text { several times }\end{array}$ & 27.4 \\
\hline $\begin{array}{l}\text { Three times per } \\
\text { month }\end{array}$ & 7.4 & 4.4 & 1.5 & 1.6 & 5.7 & 9.2 & 0.3 & 0.7 & $\begin{array}{l}\text { Once a day or } \\
\text { several times }\end{array}$ & 22.0 \\
\hline $\begin{array}{l}\text { Four times per } \\
\text { month or more }\end{array}$ & 14.0 & 4.7 & 2.5 & 1.9 & 9.7 & 19.8 & 1.5 & 0.8 & & \\
\hline Total & 100 & 100 & 100 & 100 & 100 & 100 & 100 & 100 & & 100 \\
\hline $\begin{array}{l}\text { Number of } \\
\text { cases }\end{array}$ & 880 & 880 & 878 & 879 & 875 & 874 & 877 & 880 & & 877 \\
\hline
\end{tabular}

Note: The numbers are percents except for the last row. 
Table 3. Pattern matrix for shopping attitudes.

\begin{tabular}{|c|c|c|c|c|c|}
\hline Shopping attitude statements & $\begin{array}{l}\text { Novelty } \\
\text { seeking }\end{array}$ & $\begin{array}{l}\text { Shopping } \\
\text { enjoyment }\end{array}$ & $\begin{array}{c}\text { Cost } \\
\text { consciousness }\end{array}$ & $\begin{array}{l}\text { Spontane- } \\
\text { ous shopper }\end{array}$ & $\begin{array}{c}\text { Time } \\
\text { consciousness }\end{array}$ \\
\hline I like to buy novel things. & 0.725 & & & & \\
\hline \multicolumn{6}{|l|}{ When it comes to buying things, I like to } \\
\hline follow the trends. & 0.654 & & & & \\
\hline \multicolumn{6}{|l|}{ It is important to show I am different from } \\
\hline others. & 0.625 & & & & \\
\hline I prefer novel products. & 0.599 & & & & \\
\hline Shopping is usually a chore for me. & & -0.786 & & & \\
\hline Shopping is fun. & 0.421 & 0.583 & & & \\
\hline \multicolumn{6}{|l|}{ I'm often in a hurry to be somewhere else } \\
\hline when I'm shopping. & & -0.540 & & & \\
\hline Shopping helps me relax. & & 0.470 & & & \\
\hline I generally compare prices before buying. & & & 0.760 & & \\
\hline \multicolumn{6}{|l|}{ I am generally cautious about buying novel } \\
\hline things. & & & 0.707 & & \\
\hline \multicolumn{6}{|l|}{ It's important to me to get the lowest prices } \\
\hline when I buy things. & & & 0.575 & & \\
\hline I usually do not care about product price. & & -0.439 & -0.394 & & \\
\hline \multicolumn{6}{|l|}{ When it comes to buying things, I'm pretty } \\
\hline spontaneous. & & & & 0.804 & \\
\hline I often make unplanned purchases. & & & & 0.668 & \\
\hline I generally stick to my shopping lists. & 0.669 & & & -0.492 & \\
\hline I have enough time to enjoy shopping. & & & & & -0.834 \\
\hline \multicolumn{6}{|l|}{ I'm too busy to shop as often or as long as } \\
\hline I’d like. & & & & & 0.731 \\
\hline
\end{tabular}

Extraction method: Principal component analysis with eigenvalue larger than one.

Rotation method: Oblimin with Kaiser normalization. The highest correlation between factor scores is 0.232 (between novelty seeking and spontaneous shopper).

Score estimation method: Regression

Loadings smaller than 0.34 are suppressed.

The five factors explain $55.2 \%$ of the variation in the items.

One statement, "I often introduce new trends to my friends" is dropped because of its low loading on all factors.

Source: Zhen et al. (2016) 
Table 4. Model goodness of fit.

\begin{tabular}{|l|l|}
\hline Degrees of freedom & 49 \\
\hline $\begin{array}{l}x^{2} \text { : measures discrepancy between the sample and model-implied covariance matrices; } \\
\text { the smaller the better }\end{array}$ & 94.113 \\
\hline $\begin{array}{l}x^{2} / \text { d.f.: a “relative chi-square value }\left(x^{2}\right) \text { ” corrected for degrees of freedom; the standard } \\
\text { values ranged between } 1 \text { and 5; values of } 3 \text { or less indicate a good fit and values } \\
\text { between } 3 \text { and } 5 \text { represent an acceptable fit. }\end{array}$ & 1.921 \\
\hline $\begin{array}{l}\text { Comparative Fit Index (CFI): assumes a noncentral } x^{2} \text { distribution for the worst } \\
\text { (independence) model discrepancy; values getting close to one represent a good fit. }\end{array}$ & 0.945 \\
\hline $\begin{array}{l}\text { Tucker Lewis index (TLI): also called the non-normed fit index (NNFI), depends on the } \\
\text { average size of the correlations between variables; the higher the better. }\end{array}$ & 0.916 \\
\hline $\begin{array}{l}\text { Root Mean Square Error of Approximation (RMSEA): measures the estimated } \\
\text { discrepancy between the model-implied and true population covariance matrix, } \\
\text { corrected for degrees of freedom; values less than 0.05 indicate a good fit. }\end{array}$ & 0.042 \\
\hline
\end{tabular}

Table 5. Standardized coefficients of the measurement models.

\begin{tabular}{|l|l|l|}
\hline \multicolumn{1}{|c|}{ Latent variables } & \multicolumn{1}{c|}{ Observed variables } & \multicolumn{1}{c|}{ Standardized coefficients } \\
\hline Online shopping propensity & Online shopping frequency-clothing & $0.720^{* *}$ \\
\hline Online shopping propensity & Online shopping frequency- daily goods & $0.594^{* *}$ \\
\hline Store shopping propensity & Store shopping frequency-clothing & $0.458^{* *}$ \\
\hline Store shopping propensity & Store shopping frequency- daily goods & $0.523^{* *}$ \\
\hline
\end{tabular}

Note: ${ }^{* *} p<0.05$ 
Table 6. Standardized direct and total effects of the SEM.

\begin{tabular}{|c|c|c|c|c|c|c|}
\hline \multirow[t]{2}{*}{ Variables } & \multicolumn{2}{|c|}{$\begin{array}{c}\text { Online searching } \\
\text { frequency }\end{array}$} & \multicolumn{2}{|c|}{$\begin{array}{c}\text { Online shopping } \\
\text { propensity }\end{array}$} & \multicolumn{2}{|c|}{$\begin{array}{c}\text { Store shopping } \\
\text { propensity }\end{array}$} \\
\hline & Direct & Total & Direct & Total & Direct & Total \\
\hline \multicolumn{7}{|l|}{ Endogenous variables } \\
\hline Online searching frequency & & & $0.245^{* *}$ & $0.318^{* *}$ & $0.160^{* *}$ & $0.160^{* *}$ \\
\hline \multicolumn{7}{|l|}{ Online shopping propensity } \\
\hline Store shopping propensity & & & $0.460^{* *}$ & $0.460^{* *}$ & & \\
\hline \multicolumn{7}{|l|}{ Exogenous variables } \\
\hline \multicolumn{7}{|l|}{ Socio-demographics } \\
\hline Female & $0.108^{* *}$ & $0.108^{* *}$ & & $0.142^{* *}$ & $0.233^{* *}$ & $0.251^{* *}$ \\
\hline Shopping responsibility & & & $0.090^{* *}$ & $0.133^{* *}$ & $0.093^{*}$ & $0.093^{*}$ \\
\hline Age & $-0.080^{* *}$ & $-0.080^{* *}$ & & $-0.025^{* *}$ & & $-0.013^{*}$ \\
\hline Having a driver's license & & & & $0.077^{* *}$ & $0.168^{* *}$ & $0.168^{* *}$ \\
\hline Household income & & & & $0.087^{* *}$ & $0.189^{* *}$ & $0.189^{* *}$ \\
\hline Number of children & & & $0.093^{* *}$ & $0.093^{* *}$ & & \\
\hline \multicolumn{7}{|l|}{ Internet use } \\
\hline Years of using internet & $0.199^{* *}$ & $0.199^{* *}$ & & $0.063^{* *}$ & & $0.032^{* *}$ \\
\hline Duration of internet access & $0.188^{* *}$ & $0.188^{* *}$ & $0.098^{* *}$ & $0.158^{* *}$ & & $0.030^{* *}$ \\
\hline \multicolumn{7}{|l|}{ Shopping attitudes } \\
\hline Novelty seeking & $0.128^{* *}$ & $0.128^{* *}$ & & $0.128^{* *}$ & $0.189^{* *}$ & $0.209^{* *}$ \\
\hline Shopping enjoyment & $0.152^{* *}$ & $0.152^{* *}$ & & $0.089^{* *}$ & $0.088^{*}$ & $0.133^{* *}$ \\
\hline Cost consciousness & $0.090^{* *}$ & $0.090^{* *}$ & & $0.029^{* *}$ & & $0.014^{* *}$ \\
\hline Spontaneous shopper & & & $0.109^{* *}$ & $0.109^{* *}$ & & \\
\hline Time consciousness & & & & $0.086^{* *}$ & $-0.186^{* *}$ & $-0.186^{* *}$ \\
\hline
\end{tabular}

Note: $* 0.05 \leq p<0.1 ; * * p<0.05$. 


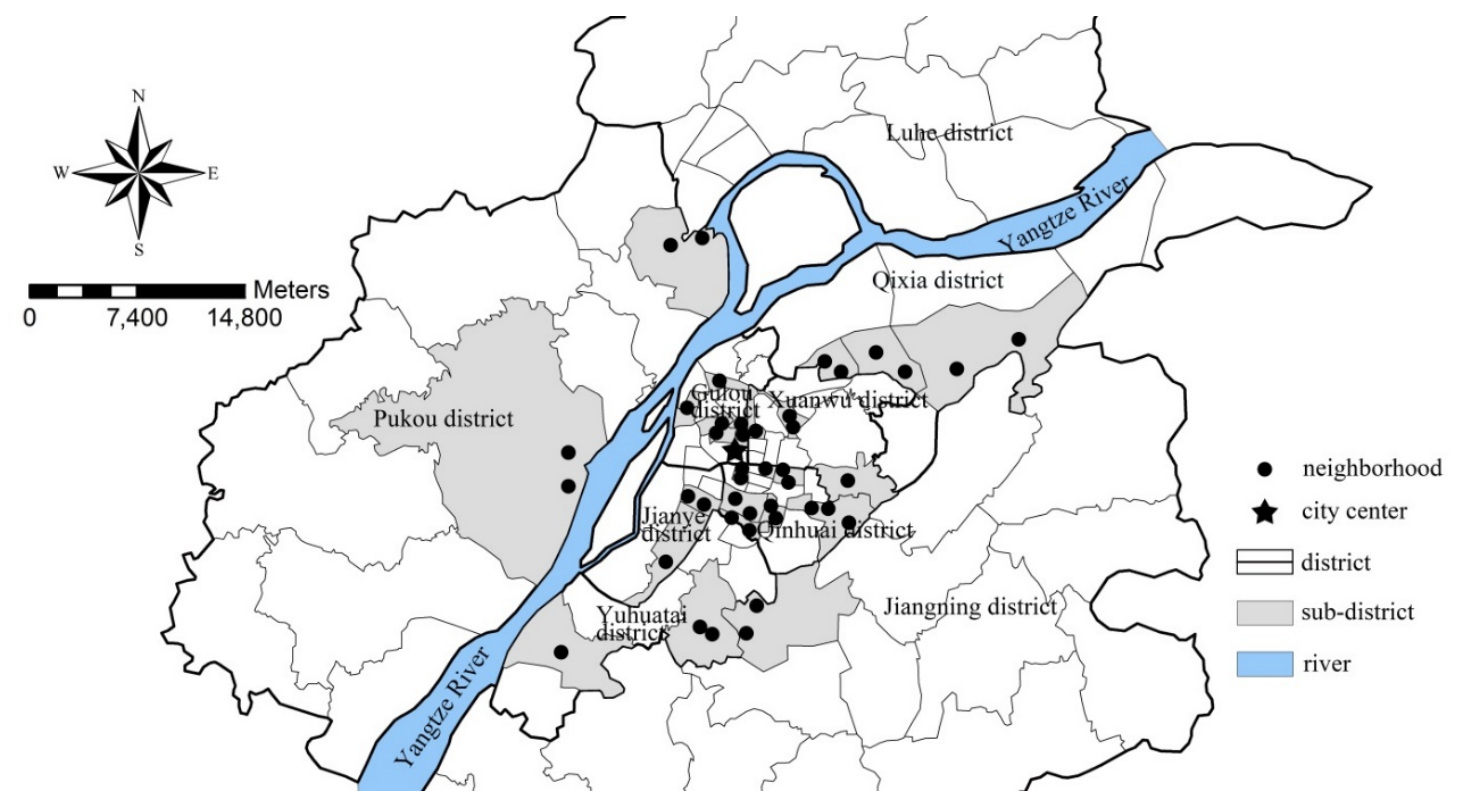

Figure 1. Geographical location of sampled neighbourhoods. Source (Zhen et al. 2016)

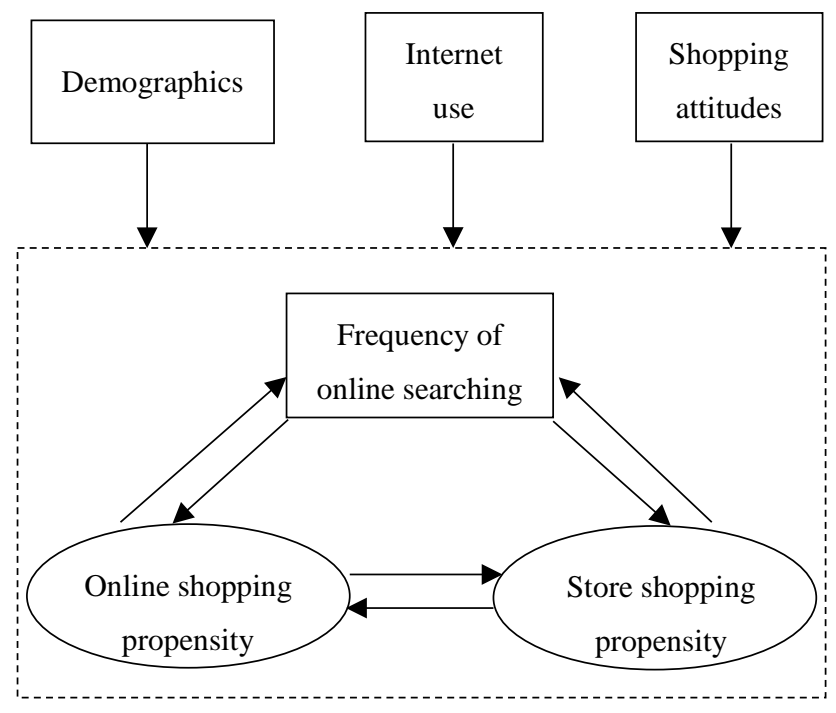

Figure 2. The conceptual model. 


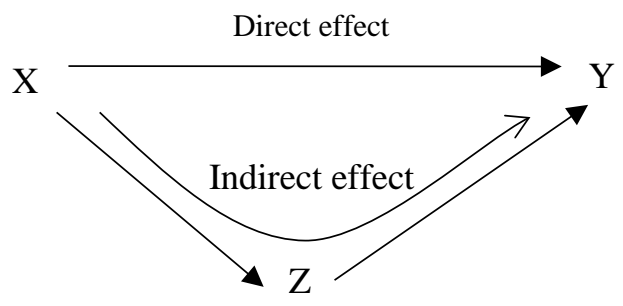

Figure 3. An illustration of direct effect and indirect effect.

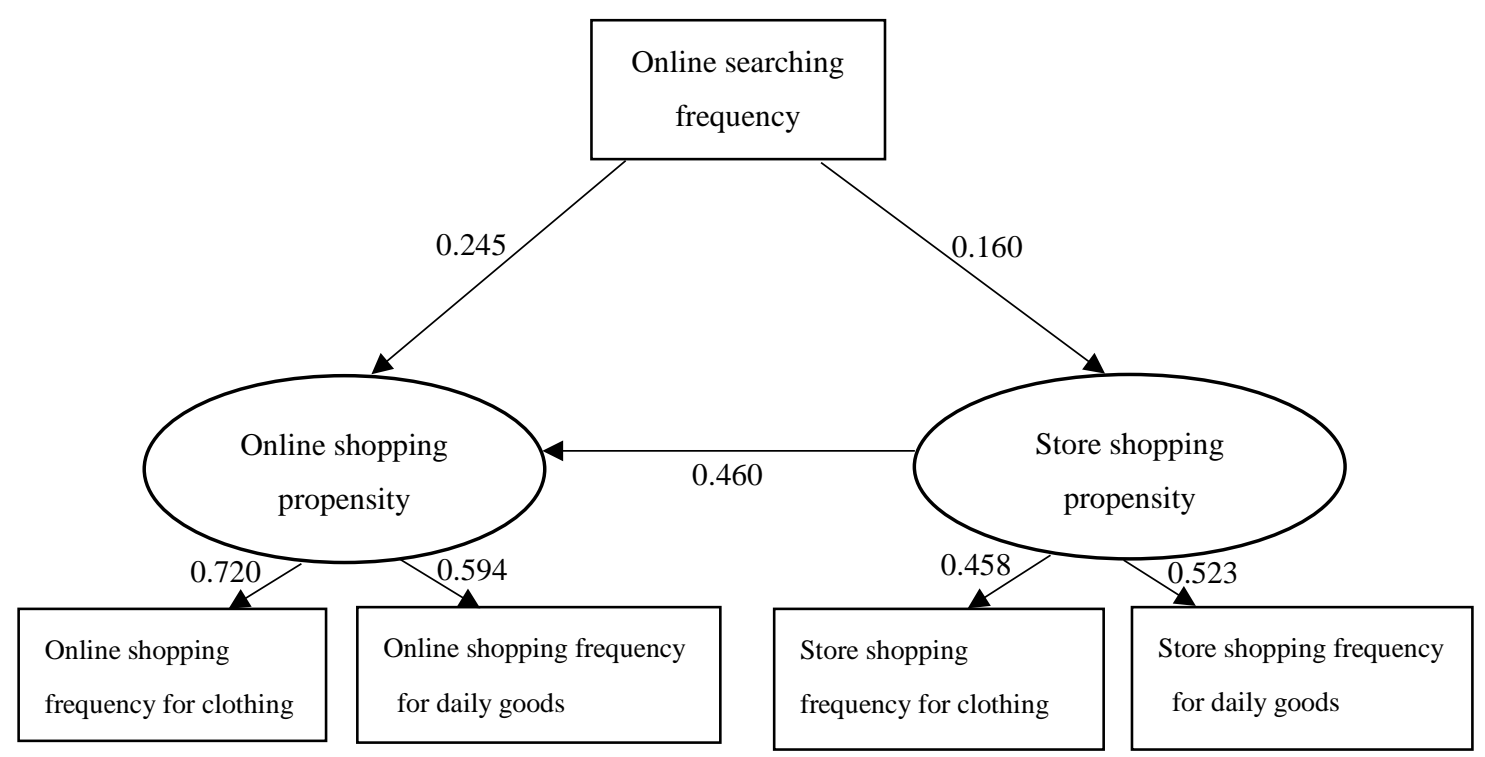

Figure 4. The relationships among three endogenous variables. 